\title{
Exfoliated Sodium Montmorillonite Reinforced Elastomeric Nanocomposites: Ablation, Thermal Transport/Decomposition/Transitions and Mechanical Aspects
}

\author{
Sadia Sagar Iqbal, Nadeem Iqbal, Tahir Jamil, and Arshad Bashir
}

\begin{abstract}
The performedresearch is used to explore the prospectiveinfluence of sodium montmorillonite (Na-MMT) on the high temperature ablation, thermal stability/conductivity and mechanical parameters of elastomeric composites. Ablation characteristics viz. (backface temperature rise, insulation index, and ablation rates)were amassed using oxyacetylene flame test. Thermal conductivity, thermal stability, ultimate tensile strength and elastomeric hardness were performed on domestically developed $\mathrm{TC}$ apparatus according ASTM E1225-99, TGA, UTM, and rubber hardness meter, respectively. The experimental data explored that with increasing Na-MMT contents in the acrylonitrile butadiene rubber, back-face temperature acclivity, linear ablation resistance, and radial ablation impedance were reduced by a factor of 95,800 , and $88 \%$, correspondingly. Maximum filler content viz. $30 \%$ has efficiently improves thermal insulation character, tensile properties and elastomeric hardness of the fabricated specimens. Microscopic results showed microporosity generation during ablation that eventually enhanced the insulation character of the ablative specimens at high temperatures. In the view of the obtained results, well dispersed Na-MMT in NBR matrix is a good combination of high as well as low temperature insulation applications.
\end{abstract}

Index Terms-Aerospace, polymer composite, oxy-acetylene flame, ablation testing, thermal analysis, mechanical properties, thermal conductivity, electron microscopy.

\section{INTRODUCTION}

An elastomerhas low density, high mechanical strength, excellenthot air resistance, and appropriate thermal stability [1]-[3]. Syntheticnitrile butadiene rubber (NBR) is a copolymer rubber of acrylonitrile \&butadiene). Chemical and Physical Properties of NBR can be changed by varying the concentration of nitrile and butadiene. NBR is unusual being used as oil/fuel/chemical resistant. The main application of NBR nanocomposites are in automotive and aeronautical industry. The second major industry is nuclear industry in which protective gloves of NBR is used. Most useful application of NBRare to makemolded goods, footwear, adhesives, sealants, sponges/expandedfoams, and floor mats etc. Mineral silicate clays are composed of different layers of plate shaped fine particles which are hydrophilic in nature due to the hydroxyl contents. $\mathrm{Si}, \mathrm{O}, \mathrm{H}$, $\mathrm{Na}, \mathrm{Ca}, \mathrm{Al}, \mathrm{Mg}$, and $\mathrm{K}$ are the major elements in the silicate based clays. Van der walls interactions are responsible for layered structure of the nanoclay. To enhanced physical and

Manuscript received June 15, 2016; revised January 12, 2017.

Sadia Sagar Iqbal is with University of the Punjab, Lahore, Pakistan(email: sadiasagariqbal.pu@gmail.com). chemical characteristics of polymeric system to develop polymer nanocomposites layered silicates are reduced to nanosize particles [4], [5]. Organic-Montmorillonite (MMT) is a mineral which in the family of phyllosilicate group. And the structure is liked octahedral sheet is sandwiched between two tetrahedral sheets. Calcium sodium aluminum magnesium silicate hydroxide is the composition of MMT along water molecules. It has1-2 mohs scale hardness of with 1.7-2 specific gravity [6]-[11]. Treated and untreated MMT has been used in different polymeric matrices (epoxy resins, poly lactic acid, melamine formaldehyde, polypropylene (PP), ethylene propylene monomer rubber (EPDM), polyurethane (PU) hydrogenated butadiene rubber HNBR, styrene butadiene rubber (SBR), silicon (SR) and acrylonitrile butadiene rubber (NBR)) to change their mechanical properties, flame retardant properties, rheological properties, shape memory effect, thermal stability, endothermic capability, and ablative characteristics [6], [7], [12], [13]. Even distribution of MMT is the main factor which enhances the thermal and mechanical properties of the nanoclay/polymer nanocomposites.

In this present study, four different amounts of sodiummontmorrilonite (Na-MMT) was incorporated in the acrylonitrile butadiene rubber (NBR) using conventional mixing method to fabricate Na-MMT/NBR nanocomposites [14]-[16]. Oxy-acetylene (O-A) flame is used to measure the ablation properties (linear/radial ablation/mass ablation rates, insulation indexes, and back-face temperature acclivity) of the Na-MMT/NBR elastomeric nanocomposites [5], [8], [17]-[19]. Thermal degradation/conductivity, heat quenching response, and mechanical properties for clay/polymer nanocomposite were also studied to confirm the effect of Na-MMT on NBR properties.

\section{EXPERIMENTAL}

TABLE I: BASE COMPOSITION OF NBR NANOCOMPOSITES WITH DIVERSE LOADING OF NA-MMT

\begin{tabular}{lcccc}
\hline \hline $\begin{array}{l}\text { Sample ID/ } \\
\text { Filler (wt\%) }\end{array}$ & $\mathbf{N 3 0}$ & $\mathbf{N 3 1}$ & $\mathbf{N 3 2}$ & $\mathbf{N 3 3}$ \\
\hline Na-MMT & 0 & 10 & 20 & 30 \\
\hline NBR: 100wt \%, Stearic Acid : 2wt \% & & \\
DOP: 7.5wt \%, Nanosilica : 15wt \%, MBTS : 2wt \%, \\
Zinc Oxide (5wt \%), TMTD: 2wt \%, Sulphur : 2wt \%), SCA: 4wt \% \\
\hline \hline
\end{tabular}

Silane coupling agent (SCA-98), Zinc oxide (ZnO), nano silica, stearic acid and sulphur (Curing agent), were received from Merck. Dioctyl phthalate (DOP) was obtained from Int. 
Petro-Chemicals Pvt. Ltd, Pakistan. Tetramethylthiuram Disulfide (TMTD) and Mercaptobenzthiazole disulphide (MBTS) were purchased from Dalian-Richon Chem. Co. Ltd., China. Sodium montmorillonite (Na-MMT) was purchased from Merck. ABF International Co. Ltd., Korea is the supplier for acrylonitrile butadiene rubber (NBR; Kumho-KNB-35L) was received from. The base formulation of NBR nanocomposite (N30) is in Table I. Three different amount of the Na-MMT are reinforced in the base composition of N30as N31 with 10 wt \%, N32 with 20 wt $\%$, and N33 with $30 \mathrm{wt} \%$.

Four diverse concentrations $(0-30 \mathrm{wt} \%)$ of Na-MMT were incorporated along with reinforcements like white carbon (nanosilica), crosslinker, accelerators, activators and plasticizers in the Acrylonitrile butadiene rubber using traditional elastomeric mixing method as premixing was occurred in internal dispersion kneader and post mixing was done on two roller mixing mill. Then to get the desire shaped for ablation, thermal and mechanical examination were moved to the isostatic hot press where temperature was $140 \mathrm{oC}$, pressure was $1600 \mathrm{psi}$ and curing time was 40 minutes. $100 \mathrm{~mm} \times 100 \mathrm{~mm} \times 10 \mathrm{~mm}$ is dimensions of composites for ablation features and ASTM D412- 98A is for tensile testing of nanocomposite specimen as shown in Fig. 1.

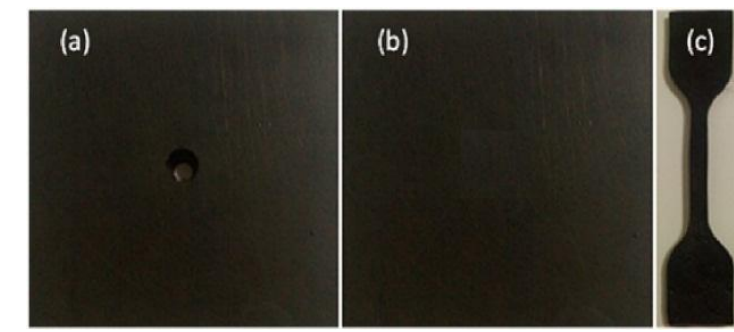

Fig. 1. Fabricated samplesimages of radial (a), linear (b) ablative and for tensile testing nanocomposites (c).

\section{CHARACTERIZATION}

ASTM E285-08 was used to test the ablation properties of the nanocomposite [20]-[22]. Experimental design of ablation measurements is depicted in Fig. 2(a), in which oxy-acetylene flame is in front on the surface of the ablator.

Three thermocouples of k-type were coupled with aluminum tape at the center of the ablator backface. TECPEL 319 data logger (with $0.1{ }^{\circ} \mathrm{C}$ resolution) and laptop along with RS-232 data cable were connected to these thermocouples. During the ablation test, $0.35 \mathrm{~m}^{3} / \mathrm{h}$ is the flow rate of both oxygen and acetylene gases. The distance between O-A flame and the surface of ablator is $10 \mathrm{~mm}$. Increase in temperature with time was observed, when the flame was in front of the nanocomposite for 100 seconds. Linear/radial ablation \& mass ablation rates, and linear \& radial percent char yield for ablators were calculated with these below formulae [22]-[26].

Linear Ablation Rate for linear ablator $(\mathrm{mm} / \mathrm{s})=$

$$
V_{P l}=\frac{\left(T_{0}-T_{1}\right)}{t}
$$

Linear Mass Ablation Rate for linear ablator $(g / s)=$

$$
V_{P m}=\frac{\left(M_{0}-M_{1}\right)}{t}
$$

$$
\text { Linear Char Yield }(\%)=Y_{P}=\frac{\left(M_{0}-M_{1}\right) * 100}{M_{0}}
$$

Radial Ablation Rate for radial ablator $(\mathrm{mm} / \mathrm{s})=$

$$
V_{R l}=\frac{\left(D_{0}-D_{1}\right)}{t}
$$

Radial Mass Ablation Rate for radial ablator $(g / s)=$

$$
V_{R m}=\frac{\left(M_{0}^{\prime}-M_{1}^{\prime}\right)}{t}
$$

$$
\begin{aligned}
& \text { Radial Char Yield }(\%)=Y_{R}=\frac{\left(M_{0}^{\prime}-M_{1}^{\prime}\right) * 100}{M_{1}} \\
& \text { Insulation Index }(\mathrm{s} / \mathrm{m})=I_{T}=\frac{t_{T}}{T_{0}}
\end{aligned}
$$

where

$M_{0}, T_{0}, \& M_{1}, T_{1}$, are the mass \&thickness of the linear ablator; $M_{0}^{\prime}, D_{0}, \& M_{1}^{\prime}, D_{1}$ are mass \&diameter of the radial ablator before and later O-A torchcontact, correspondly and the total time for ablation tes is t. $I_{T}$ is the time to take to increase the backface temperature at a specific temperature (T) and $T_{0}$ is the thickness of specimen.

Thermal degradation/endothermic/exothermic response of the Na-MMT/NBR nanocomposites were analyzed through Diamond Perkin-Elmer TG/DTA with scan speed of $10^{\circ} \mathrm{C} / \mathrm{min} \& 25-1000^{\circ} \mathrm{C}$ was the temperature range.

E1225-99ASTM was adopted to calculate the thermal conductivity $\left(\lambda_{N}\right)$ of the Na-MMT/NBR nanocomposite specimens. The specimen dimension was 1 inch $^{2}$ area and $3 \mathrm{~mm}$ thickness. Schematic diagram of comparative longitudinal heat flow method in Fig. 2(b) indicates the position of thermocouples, heater, data logger with laptop system, and heat sink. Copper plates were used as a reference for the calculation of $\lambda_{N}$. Time-temperature curves of six thermocouples were observed on the laptop through 6 point data-logger.
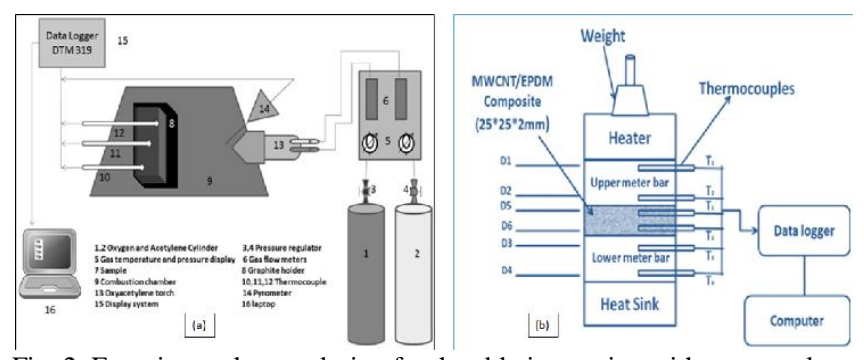

Fig. 2. Experimental setup design for the ablation testing with oxyacetylene flame (a) and schematic diagram of the thermal conductivity calculation (b) of the Na-MMT/NBR nanocomposites.

$\lambda_{N}$ of the Na-MMT/NBR nanocomposite specimens was measured using Equation 8 [27], [28].

Thermal conductivity of specimen $(\mathrm{W} / \mathrm{m}-\mathrm{K})$

$$
\lambda_{N}=\lambda_{s} \frac{\left(Q_{T}^{\prime}+Q_{B}^{\prime}\right)\left(D_{4}-D_{3}\right)}{2\left(T_{4}-T_{3}\right)}
$$

where

Top bar heat flow $=Q_{T}^{\prime}=\frac{\lambda_{S}\left(T_{2}-T_{1}\right)}{D_{2}-D_{1}}$

Bottom bar heat flow $=Q_{B}^{\prime}=\frac{\lambda_{S}\left(T_{6}-T_{5}\right)}{D_{6}-D_{5}}$

$\lambda_{S}=$ Thermal conductivity of the copper plates

$T_{1}, T_{2}, T_{3}, T_{4}, T_{5}$, and $T_{6}$ are the temperatures of six thermocouples and $D_{1}, D_{2}, D_{3}, D_{4}, D_{5}$, and $D_{6}$ are the positions of these six thermocouples. 
Mechanical testing of the Na-MMT/NBR ablative nano composite specimens was conduct withAG-20KNXDPlus,Shimadzu, China, Universal Testing Machine (UTM) with the reference of D-412-98A ASTM standard and hardness is calculated in Shore A of the Na-MMT/NBR nanocomposites which was measured on Torsee, Tokyo testing machine.

Even dispersion, spongy char structure, formation of silica, char reinforcement reaction and composition ofchar of burnt ablators were examined with Scanning Electron Microscopy (SEM; 6490A JSM - Jeol, Japan) joined energy dispersive spectroscopy (EDS) [9], [29]. For SEM examination nanocomposite specimens were fractured in the liquid nitrogen and then cross-sectional area of gold coated specimens was examined to study the Na-MMT distribution in the host rubber.

\section{RESUlTS AND DisCUSSION}
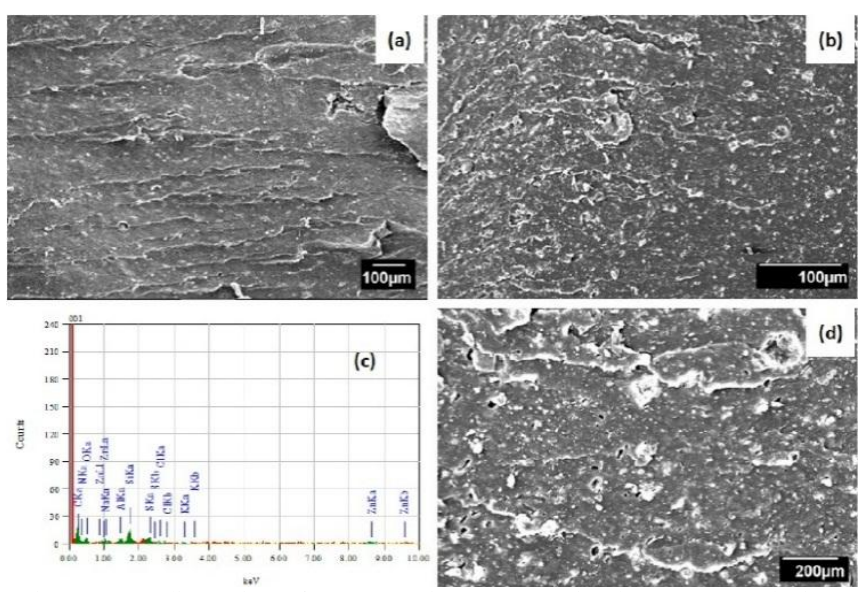

Fig. 3. Even dispersion of Na-MMT in NBR Matrix along EDS analysis.

Even distribution of Na-MMT in NBR was attained with a internal dispersion kneader (pre-mixing) \& two-roller mixing mill (post-mixing). The SEM images at two different magnifications $(100 \mu \mathrm{m} \& 200 \mu \mathrm{m})$ as in Fig. 3(a, b $\&$ d) confirm the uniform distribution of Na-MMT in the host matrix. Elemental analysis of Na-MM Treinforced in NBR is showed as depicted in Fig. 3(c) that evident the presence of Na-MMT in NBR matrix. Cyclic three dimensional rotation of elastomer material over the twice rolls slip of two-roller mixing mill and internal dispersion kneader exercise makes distribution good within the host NBR matrix [2].

Decrease in back face temperature acts a significant part in the ablation behavior of an ablator. Fig. 4 explains the back-face temperature data recorded, when the O-A flame was in contact on the facet of linear ablator for 200s. In the first 100s flame contact, temperature evolution is minordue to the reradiational, transpirational, evaporational, and polymer pyrolysis that occur inside the ablative nanocomposites when ablation test was performed. In after 100 s of time- temperature curve of the ablation testing, back-face temperature elevation is increased due to thermal agitation or phonon transportation [30].

Table II illustrates backface temperature progress rate (BTPR) and the ultimate backface temperatures (UBT) of the Na-MMT/NBR nanocomposite specimens from the time-temperature curves [2], [31], [32]. UBT and BTPR are decreased significantly with increasingthe Na-MMT amount in the NBR. Due to the incorporation of maximum loading of nanofillers into NBR matrix decrease the UBT up to $71^{\circ} \mathrm{C}$ and BTPR up to $55 \%$. Table II presents the insulation indexes of the nanofiller/NBR ablative specimen at three different temperatures [33], [34]. It is cleared that Na-MMT has commendablyincreased the insulation character of the Na-MMT/NBR nanocomposite ablator due to its outstanding heat absorbing properties. Na-MMT has low thermal conductivity and high heat capacity which efficiently reduces the back-face rise in temperature during ablation testing.

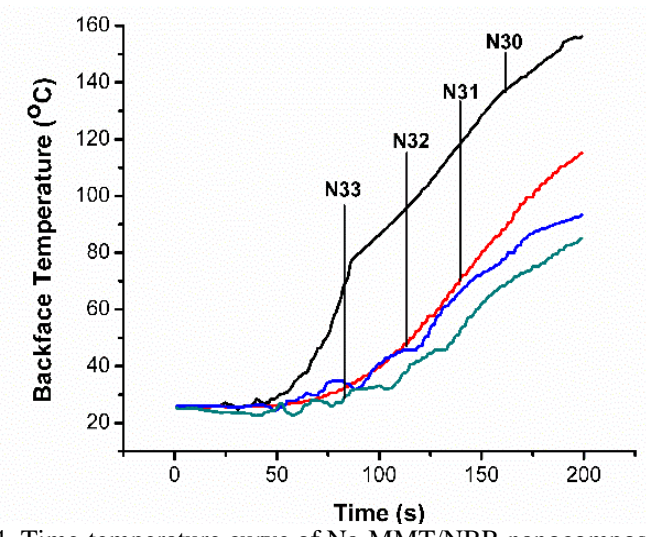

Fig. 4. Time-temperature curve of Na-MMT/NBR nanocomposites with different filler doping

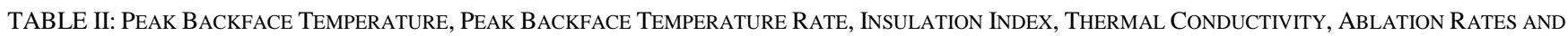
PERCENT CHAR YIELD OF NA-MMT/NBR NANOCOMPSOITES

\begin{tabular}{|c|c|c|c|c|}
\hline Properties/ Sample ID & N30 & N31 & N32 & N33 \\
\hline Peak Back-face Temperature $\left({ }^{\circ} \mathrm{C}\right)$ & $156.02 \pm 0.001$ & $115.12 \pm 0.001$ & $93.34 \pm 0.001$ & $85.13 \pm 0.001$ \\
\hline Back-face Temperature Rate $\left({ }^{\circ} \mathrm{C} / \mathrm{s}\right)$ & $0.65045 \pm 0.001$ & $0.449 \pm 0.001$ & $0.3405 \pm 0.001$ & $0.296 \pm 0.001$ \\
\hline Insulation Index $(\mathrm{s} / \mathrm{m})$ at $60^{\circ} \mathrm{C}$ & $7931 \pm 1$ & $12863 \pm 1$ & $13074 \pm 1$ & $14807 \pm 1$ \\
\hline Insulation Index $(\mathrm{s} / \mathrm{m})$ at $70^{\circ} \mathrm{C}$ & $8447 \pm 1$ & $13924 \pm 1$ & $14590 \pm 1$ & $16567 \pm 1$ \\
\hline Insulation Index $(\mathrm{s} / \mathrm{m})$ at $80^{\circ} \mathrm{C}$ & $9036 \pm 1$ & $15057 \pm 1$ & $16601 \pm 1$ & $18750 \pm 1$ \\
\hline Thermal Conductivity $\left(\mathrm{W} / \mathrm{m}^{\circ}{ }^{\circ} \mathrm{C}\right)$ at $100^{\circ} \mathrm{C}$ & $0.15609 \pm 0.01$ & $0.15082 \pm 0.01$ & $0.14046 \pm 0.01$ & $0.12942 \pm 0.01$ \\
\hline Linear Ablation Rates & $0.087 \pm 0.001$ & $0.075 \pm 0.0015$ & $0.031 \pm 0.0016$ & $0.002 \pm 0.0017$ \\
\hline Linear mass ablation rates & $0.467 \pm 0.01$ & $0.343 \pm 0.01$ & $0.337 \pm 0.015$ & $0.211 \pm 0.01$ \\
\hline Linear Percent Char Yield & $22.736 \pm 0.36$ & $16.872 \pm 0.32$ & $16.184 \pm 0.34$ & $10.387 \pm 0.31$ \\
\hline Radial Ablation Rates & $0.236 \pm 0.0014$ & $0.217 \pm 0.0015$ & $0.178 \pm 0.0016$ & $0.167 \pm 0.0017$ \\
\hline Radial mass ablation rates & $0.135 \pm 0.001$ & $0.133 \pm 0.001$ & $0.167 \pm 0.001$ & $0.093 \pm 0.001$ \\
\hline Radial Percent Char Yield & $7.346 \pm 0.25$ & $6.498 \pm 0.21$ & $5.453 \pm 0.24$ & $4.796 \pm 0.23$ \\
\hline
\end{tabular}

Thermal conductivity response with three different concentrations of Na-MMT loaded NBR nanocomposites is tabulated in Table II. It is cleared that with increasing the
Na-MMT loading in NBR, thermal conductivity of NaMMT/NBR nanocomposite increased consequently. The $0.128 \mathrm{~W} / \mathrm{m}^{-}{ }^{\circ} \mathrm{C}$ is lowest thermal conductivity for $\mathrm{N} 33$ due to 
the remarkable thermal efficiency of the reinforced nanofiller. It is attributed due to the incoming heat energy consumption to evaporate the associated water molecules with the incorporated Na-MMT. The second thing is the high heat capacity and Na-MMT developed network that resists the heat transport through the composite specimens. Low thermal conductivity of the Na-MMT reinforced elastomeric nanocomposite endorses it for low temperature application viz. automobiles, construction industry, air vehicle industry, etc.

According to ASTM standard, linear/mass ablation rates/ percent char yield were measured to ablation resistance and the collective statistics are tabulated in Table II. As per Table II, 98\% linear ablation rate and 54\% linear mass ablation rate is dropped down with $30 \mathrm{wt} \%$ incorporation of the Na-MMT in the NBR host matrix while $55 \%$ char yield increased. This is evidence of nanofillers thermal responses and good compatibility with polymer matrix. The silane coupling agent as coupling ingredient helps to makes a strong bonding of polymer with nanofiller which plays a significant role to increase compatibility and dispersibility level within the matrix and ultimately effects the thermal, mechanical, and ablation properties of the Na-MMT/NBR nanocomposite specimens[22].

The cavity of the radial ablator is designed to pass $\mathrm{O}$ Aflame for 200 s to measure the radial ablation/mass ablation rates and char yield in percent of Na-MMT/NBR nanocomposite and the collected results are tabulated in Table II. Reduction is recorded from 0.22 to $0.17 \mathrm{~mm} / \mathrm{s}$ for radial ablation rate, 0.11 to $.09 \mathrm{mg} / \mathrm{s}$ for radial mass ablation rate and 7.33 to $4.75 \%$ for radial present char yield withmaximum incorporation of Na-MMTto the main composition N30. This was wonderful presentation of NaMMT along with the silane coupling agent approve its efficacy to enhance linear and radial ablation resistance of the Na-MMT/NBR nanocomposite specimens [35], [36].

Ablation phenomena (Silica melting, pyrolysis and char reinforcement reaction) is clearly visible in SEM micrographs as in Fig. 5(a, b, c, d) of the maximum loaded Na-MMT/NBRablative nanocomposite. Transpirational and vaporizational cooling effects are also plays an important role to reduce the back face temperature of the ablator which is observed in SEM images as the form of generated microporosity during ablation of the Na-MMT/NBR nanocomposite [37]-[39].

Photographs of post burn specimens of linear and radial ablated specimens are depicted in Fig. 5(e, f). It is clears from the Fig. 5(e, f) Na-MMT/NBR nanocomposite specimen own excellent mechanical erosion resistance because of goodbonding between the virgin material and the char zone. This excellent property support this type of ablator to use on the surface of the space vehicle to survive the hyper-thermal environment [22].

$\%$ Mass loss measurements is recorded in the temperature range of $25-750^{\circ} \mathrm{C}$ for Na-MMT incorporated NBR specimens. Fig. 6(a) contains the collected statistics of thermal stability of fabricated nanocomposite specimens which shows $6 \%$ mass loss at $130^{\circ} \mathrm{C}$ because of evaporation of the aromatic oil and decomposition of processing aids but the system shows marvelous thermal stability up to $280^{\circ} \mathrm{C}$. The maximum thermal degradation is recorded between $411-474^{\circ} \mathrm{C}$ temperature range while with the same temperature range, nanofillers loaded NBR matrix has respond extraordinarilyas in Fig. 6(a). Thermal degradation of host NBR matrix was improved with increment of nanoloading. Fig. 6(a) clears that $2 \%$ increase in thermal durability of Na-MMT/NBR nanocompositeat $650^{\circ} \mathrm{C}$ with maximum Na-MMT loading in host NBR matrix owing to the good distribution and low thermal degradation of the Na-MMT in the NBR [40], [41].
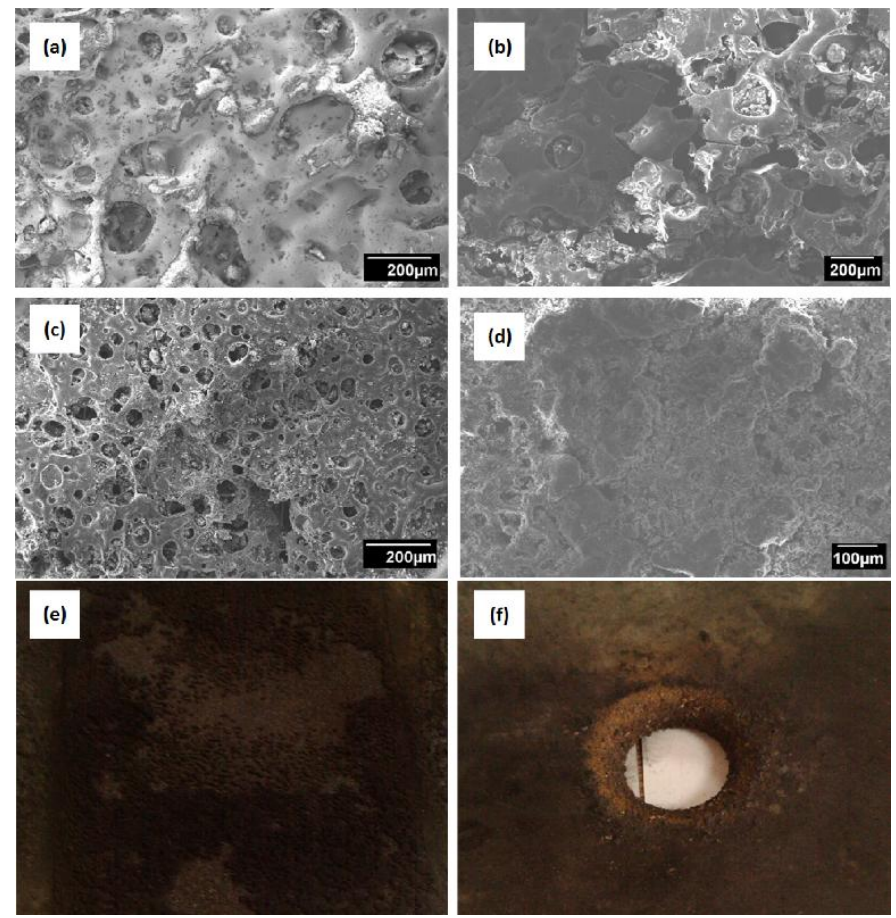

Fig. 5. SEM images maximum loaded ablated specimen (a, b, c, d) and post burnt photographs of linear (e) and radial (f) of $30 \mathrm{wt} \%$ loaded NaMMT/NBR ablated nanocomposite.

It is attributed due to the high melting point, high heat capacities and low thermal conductivity of the nanoreinforcements. Fig. 7 shows the differential thermal analysis (DTA) thermograms of the temperature range (25$850^{\circ} \mathrm{C}$ ) in ambient atmosphere of Na-MMT/NBR nanocomposites. Enormous heat is absorbed to vaporize the lubricants, burning of aids, dehydrate of nanofillers and accelerate the polymer molecules vibration to break the chemical bonding within the host matrixupto $500^{\circ} \mathrm{C}$. The heat quenching capability of Na-MMT/NBR nanocomposite specimens has progressively increased by the addition of nanofiller inpolymer due to the dehydration and phase variations produced within the nanofiller during thermal analysis.

The universal mechanical testing of Na-MMT/NBR nanocomposite was performed according to the ASTM and collective results are assembled in Fig. 8. The toughness of the Na-MMT/NBR nanocomposite is increased with increasing Na-MMT/NBR amount in the NBR matrix. Table IIItabulates that the ultimate tensile strength (UTM) is increased whil emaximum elongation to failure of the $\mathrm{Na}$ MMT/NBR nanocomposites is decreased with the increasing concentration of the nanofiller in the NBR due to the good Nano scale attachment of nanofillers with polymeric chains in which the nanofillerplays an excellent role to prevent molecular displacement within the chains of 
polymer during the mechanical testing, respectively[3], [42], [43].

Elastic modulus at 100 and $150 \%$ elongations has been increased up to 17 and $25 \%$ with the base composition N30due to excellent Na-MMT/polymer compatibility and good filler distribution in the NBR matrix as tabulated in Table III [44].

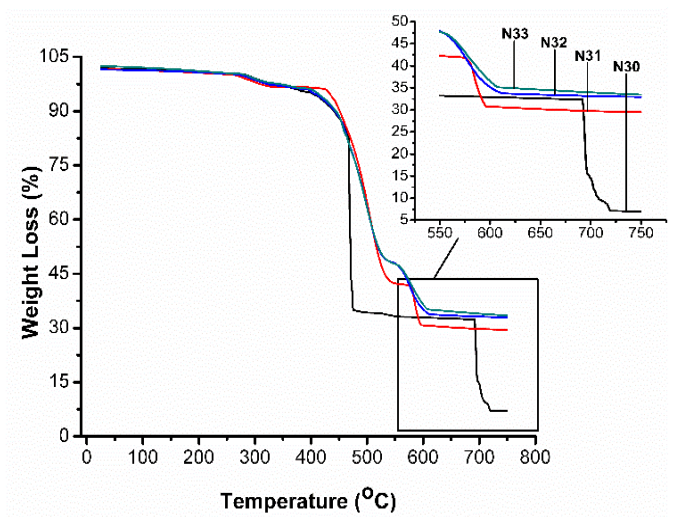

Fig. 6. TGA nanofillers reinforced with different loading in NBR matrix.

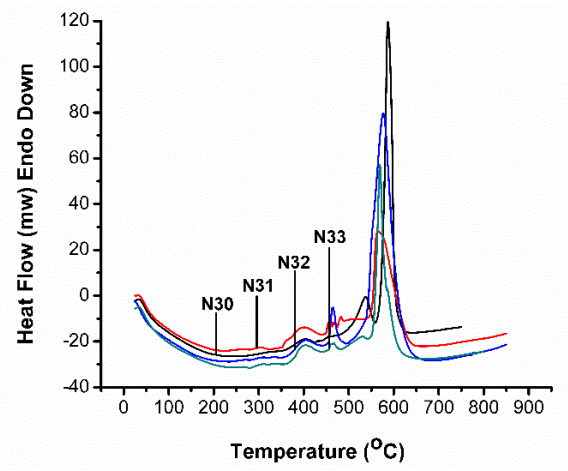

Fig. 7. Differential thermal analysis nanofillers reinforced with different loading in NBR matrix.

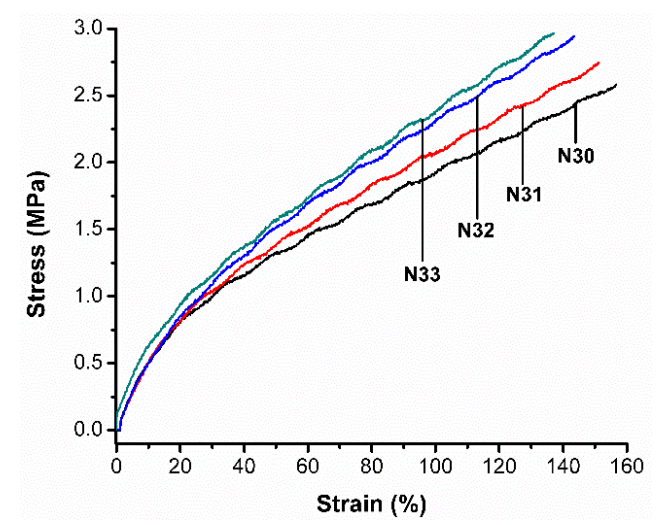

Fig. 8. Stress-strain curve of Na-MMT/NBR nanocomposites with different Na-MMTloadings in the NBR matrix.

TABLE III: UTS, ElONGATION AT BREAK, MODULUS AT 100 AND 150\% ELONGATION AND HARDNESS FOR NA-MMT/NBR NANOCOMPOSITE

\begin{tabular}{cccccc}
\hline $\begin{array}{c}\text { Sample } \\
\text { ID }\end{array}$ & $\begin{array}{c}\text { Ultimate } \\
\text { Tensile } \\
\text { Strength } \\
(\mathbf{M P a})\end{array}$ & $\begin{array}{c}\text { Elongation } \\
\text { at Break } \\
(\%)\end{array}$ & $\begin{array}{c}\mathbf{1 0 0 \%} \\
\text { Modulus } \\
(\mathbf{M P a})\end{array}$ & $\begin{array}{c}\mathbf{1 5 0 \%} \\
\text { Modulus } \\
(\mathbf{M P a})\end{array}$ & $\begin{array}{c}\text { Hardness } \\
\text { (Shore A) }\end{array}$ \\
\hline $\mathbf{N 3 0}$ & 2.58282 & 156.6773 & 2.658 & 1.91745 & 52 \\
$\mathbf{N 3 1}$ & 2.74379 & $\begin{array}{c}151.2469 \\
5\end{array}$ & 2.768 & 2.06464 & 57 \\
$\mathbf{N 3 2}$ & 2.94316 & $\begin{array}{c}143.4455 \\
3\end{array}$ & 3.025 & 2.31877 & 60 \\
$\mathbf{N 3 3}$ & 2.96781 & $\begin{array}{c}137.1807 \\
4\end{array}$ & 3.121 & 2.37989 & 64 \\
\hline
\end{tabular}

Shore A rubber hardness of the NBR nanocomposite specimens was calculated and the data are tabulated in Table III. NBR hardness is increased with rising amount of the Na-MMT in the NBR matrix up to 7 Shore A in comparison of N30owing to the decreased matrix flow ability with increment nanofiller to host polymerproportion and uniform distribution of the layered silicate mineral clay (Na-MMT) in the rubber (NBR) matrix[45]. The incorporated nanofiller decreased the plasticity of host elastomer which ultimatelyimproves elastomeric hardness of the $\mathrm{Na}$ MMT/NBR nanocomposite.

\section{CONCLUSION}

Conventional method of elastomeric mixing is adopted to reinforced Na-MMT in NBR matrix to fabricated NaMMT/NBR ablator nanocomposite. The comprehensive ablation study of the Na-MMT/NBR nanocomposite specimens discloses that $30 \%$ incorporation of the nanofiller has decreased backface temperature meanwhile $52 \%$ at $80^{\circ} \mathrm{C}$ backface temperature relative to the base composition N30 has been increased the insulation index. The even distribution of the nanoreinforcement (Na-MMT) has effective to recorddecreased the ablation rates of the $\mathrm{Na}$ MMT/NBR nanocomposite. Thermal stability, thermal conductivity and heat quenching capability of the NaMMT/NBR nanocomposite specimens have also increased with increasing nanofillerquantity in the host NBR matrix. Mechanical characteristics of the fabricated Na-MMT/NBR nanocomposite have also progressively enhanced owing to the goodmatrix-nanofiller compatibility and distribution within the matrix.The addition of Na-MMT along with the silane coupling agent is permitted to increase the thermal, ablation and mechanical properties of host polymer NBR matrix [46].

\section{ACKNOWLEDGEMENT}

The authors have greatly acknowledged University of the Punjab, Lahore, Pakistan; for research grant of fiscal year 2015-2016 to fulfill this research. Also, authors have thankful to Mr. Sheikh Iftikhar Ahmed, MD Longman mills for providing facilities regarding fabrication of nanoablative specimens; Pakistan Railways Carriage Factory, Islamabad for ablation testing, Dr. Mohammad Mujahid, Principal SCME, NUST for SEM/EDS analysis, Dr. Muhammad Shahid, HoD Dept. of Materials Engineering, SCME, NUST, Islamabad for mechanical analysis, and Dr. Bilal Khan, Principal CES, NUST, Islamabad for his expert opinions.

\section{REFERENCES}

[1] S. Sagar, N. Iqbal, A. Maqsood, and U. Javaid, "Thermogravimetric, differential scanning calorimetric and experimental thermal transport study of MWCNT/NBR nanocomposites," J. Therm. Anal. Calorim., vol. 114, pp. 161-167, 2013.

[2] N. Iqbal, S. Sagar, M. B. Khan, and H. M. Rafique, "Ablation, thermal stability/transport and mechanical investigations of modified nanokaolinite impregnated acrylonitrile butadiene rubber composites," J. Compos. Mater., vol. 48, pp. 1221-1231, 2013.

[3] R. F. Gibson, "Damping characteristics of composite materials and structures," J. Mater. Eng. Perform., vol. 1, pp. 11-20, 1992.

[4] K. Fukushima, D. Tabuani, and G. Camino, "Poly (lactic acid)/clay nanocomposites: Effect of nature and content of clay on morphology, thermal and thermo-mechanical properties," Mater. Sci..Eng.: C, 2012 . 
[5] W. S. Lin, "Steady ablation on the surface of a two-layer composite," Int J Heat Mass Tran, vol. 48, pp. 5504-5519, Oct. 2005.

[6] W. Xie, Z. Gao, W. P. Pan, D. Hunter, A. Singh, and R. Vaia, "Thermal degradation chemistry of alkyl quaternary ammonium montmorillonite," Chemistry of Materials, vol. 13, pp. 2979-2990, 2001.

[7] H. Ma, L. Tong, Z. Xu, and Z. Fang, "Synergistic effect of carbon nanotube and clay for improving the flame retardancy of ABS resin," Nanotechnology, vol. 18, pp. 375602, 2007.

[8] J. M. Esfahani, M. Esfandeh, and A. R. Sabet, "High-velocity impact behavior of glass fiber-reinforced polyester filled with nanoclay," $J$. Appl. Polym. Sci., 2012.

[9] A. R. Bahramian, M. Kokabi, M. H. N. Famili, and M. H. Beheshty, "High temperature ablation of kaolinite layered silicate/phenolic resin/asbestos cloth nanocomposite," J. Hazard Mater., vol. 150, pp. 136-145, May 2008

[10] A. Das and K. W. Stöckelhuber, R. Jurk, D. Jehnichen, and G. Heinrich, "A general approach to rubber-montmorillonite nanocomposites: Intercalation of stearic acid," Appl. Clay Sci., vol. 51, pp. 117-125, 2011.

[11] R. Liao, F. Zhang, and L. Yang, "Electrical and thermal properties of kraft paper reinforced with montmorillonite," J. Appl. Polym. Sci., 2012.

[12] E. S. Kim, E. J. Kim, T. H. Lee, and J. S. Yoon, "Clay modification and its effect on the physical properties of silicone rubber/clay composites," J. Appl. Polym. Sci., vol. 125, pp. E298-E304, 2012.

[13] A. K. Panda, B. Mishra, D. Mishra, and R. Singh, "Effect of sulphuric acid treatment on the physico-chemical characteristics of kaolin clay," Colloid Surface A, vol. 363, pp. 98-104, 2010.

[14] L. Conzatti, P. Stagnaro, G. Colucci, R. Bongiovanni, A. Priola, A. Lostritto, and M. Galimberti, "The clay mineral modifier as the key to steer the properties of rubber nanocomposites," Appl. Clay Sci., vol. 61, pp. 14-21, 2012.

[15] [15] M. Balachandran, S. Devanathan, R. Muraleekrishnan, S. Bhagawan, "Optimizing properties of nanoclay-nitrile rubber (NBR) composites using face centered central composite design," Mater. Design, vol. 35, pp. 854-862, 2012.

[16] [16] Q. Zhou, M. Xanthos, "Nanosize and microsize clay effects on the kinetics of the thermal degradation of polylactides," Polym. Degrad. Stabil., vol. 94, pp. 327-338, 2009.

[17] Y. I. Dimitrienko, "Thermal stresses in ablative composite thinwalled structures under intensive heat flow," Int. J. Eng. Sci., vol. 35 pp. 15-31, 1997.

[18] E. Venkatapathy, J. Arnold, B. Laub, and G. Hartman, "Thermal protection system development, testing and qualification," Advances in Space Research Adv. Space Res., p. 3320, Dec 2008.

[19] L. Torre, J. Kenny, and A. Maffezzoli, "Degradation behaviour of a composite material for thermal protection systems Part IExperimental characterization," J. Mater. Sci., vol. 33, pp. 3137-3143, 1998.

[20] N. Iqbal, M. B. Khan, S. Sagar, and A. Maqsood, "Fabrication and characterization of multiwalled carbon nanotubes/silicone rubber composites," J. Appl. Polym. Sci., vol. 128, pp. 2439-2446, May 2013

[21] N. Iqbal, S. Sagar, and M. B. Khan, "Comprehensive ablation characteristics of ceramic fibers impregnated rubber composites," Int. J. Eng. Tech., vol. 6, pp. 162-167, 2014.

[22] Y. Guan, L. X. Zhang, L. Q. Zhang, and Y. L. Lu, "Study on ablative properties and mechanisms of hydrogenated nitrile butadiene rubber (HNBR) composites containing different fillers," Polym. Degrad. Stabil., vol. 96, pp. 808-817, 2011.

[23] Y. J. Wang, H. J. Li, Q. G. Fu, H. Wu, D. J. Yao, and B. B. Wei, "Ablative property of HfC-based multilayer coating for C/C composites under oxy-acetylene torch," Appl. Surf. Sci., vol. 257, pp. 4760-4763, 2011.

[24] G. Gao, Z. Zhang, X. Li, Q. Meng, Y. Zheng, Z. Jin, "Effect of weight ratio of thermoplastic and thermosetting boron-containing phenolic resin on mechanical, bonding, and ablative properties of thermal insulating composites," J. Appl. Polym. Sci., Vol. 118, pp. 266-274, 2010

[25] G. Gao, Z. Zhang, Y. Zheng, and Z. Jin, "Effect of fiber orientation angle on thermal degradation and ablative properties of short-fiber reinforced EPDM/NBR rubber composites," Polym. Compos., vol. 31 pp. 1223-1231, 2010.

[26] L. Torre, J. Kenny, and A. Maffezzoli, "Degradation behaviour of a composite material for thermal protection systemsPart II Process simulation," J. Mater. Sci., vol. 33, pp. 3145-3149, 1998.

[27] S. Sagar, N. Iqbal, A. Maqsood, M. Shahid, N. A. Shah, T. Jamil, and M. I. Bassyouni, "Fabrication and thermal characteristics of functionalized carbon nanotubes impregnated polydimethylsiloxane nanocomposites," J. Compos. Mater., p. 0021998314528733, 2014.
[28] S. Sagar, N. Iqbal, and A. Maqsood, "Multiwalled carbon nanotubes impregnated rubber nanocomposites: thermal transport/decomposition and differential scanning calorimetric study,” J. Reinfor. Plast.Compos., vol. 32, pp. 1052-1061, 2013.

[29] W. Yi, X. Yongdong, W. Yiguang, C. Laifei, and Z. Litong, "Effects of $\mathrm{TaC}$ addition on the ablation resistance of $\mathrm{C} / \mathrm{SiC}$," Mater. Lett., vol. 64, pp. 2068-2071, 2010.

[30] M. Firouzmanesh and A. A. Azar, "Study of thermal stability and ablation behavior of carbon/epoxy-novolac composites," J. Appl. Polym. Sci., vol. 88, pp. 2455-2461, 2003.

[31] A. R. Bahramian and M. Kokabi, "Ablation mechanism of polymer layered silicate nanocomposite heat shield," J. Hazard Mater., vol. 166, pp. 445-454, Nov. 2008.

[32] A. R. Bahramian, M. Kokabi, M. H. N. Famili, and M. H. Beheshty, "Ablation and thermal degradation behaviour of a composite based on resol type phenolic resin: Process modeling and experimental," Polymer, vol. 47, pp. 3661-3673, 2006.

[33] T. S. Najim, M. Amel, and M. M. Barbooti, "Thermal and ablative properties of ipns and composites of high ortho resole resin and difurfurylidene acetone," Leonardo Electron J. Pract. Tech., vol. 7, pp. 34-46, 2008.

[34] J. K. Park and T. J. Kang, "Thermal and ablative properties of low temperature carbon fiber-phenol formaldehyde resin composites," Carbon, vol. 40, pp. 2125-2134, 2002.

[35] M. Bassyouni, N. Iqbal, S. S. Iqbal, S.-S. Abdel-hamid, M. AbdelAziz, U. Javaid, and M. B. Khan, "Ablation and thermo-mechanical investigation of short carbon fiber impregnated elastomeric ablatives for ultrahigh temperature applications," Polym. Degrad. Stabil., vol 110, pp. 195-202, 2014.

[36] S. S. Iqbal, N. Iqbal, T. Jamil, A. Bashir, and Z. M. Khan, "Tailoring in thermomechanical properties of ethylene propylene diene monomer elastomer with silane functionalized multiwalled carbon nanotubes," J. Appl. Polym. Sci., vol. 133, 2016.

[37] L. Torre, J. Kenny, G. Boghetich, and A. Maffezzoli, "Degradation behaviour of a composite material for thermal protection systems Part III Char characterization,” J. Mater. Sci., vol. 35, pp. 4563-4566, 2000.

[38] M. B. Khan, N. Iqbal, and Z. Haider, "Transpiration Cooling Assisted Ablative Thermal Protection of Aerospace Substructures," Key Eng. Mater., vol. 442, pp. 34-40, 2010.

[39] N. Iqbal, S. Sagar, M. B. Khan, M. I. Bassyouni, and Z. M. Khan, "Aluminum silicate fibers impregnated acrylonitrile butadiene rubber composites: Ablation, thermal transport/stability, and mechanical inspection," J. Appl. Polym. Sci., vol. 130, pp. 4392-4400, 2013.

[40] M. A. Raza, A. V. K. Westwood, C. Stirling, and N. Hondow, "Transport and mechanical properties of vapour grown carbon nanofibre/silicone composites," Compos. Pt. A-Appl. Sci. Manuf., vol. 42, pp. 1335-1343, 2011

[41] N. Iqbal, S. Sagar, M. B. Khan, and H. M. Rafique, "Elastomeric ablative nanocomposites used in hyperthermal environments," Polym. Eng. Sci., vol. 54, pp. 255-263, 2013.

[42] T. J. Kang, S. J. Shin, K. Jung, and J. K. Park, "Mechanical, thermal and ablative properties of interply continuous/spun hybrid carbon composites," Carbon, vol. 44, pp. 833-839, Jan. 2006.

[43] M. Grujicic, R. Yavari, J. Snipes, S. Ramaswami, T. Jiao, and R. Clifton, "Experimental and computational study of the shearing resistance of polyurea at high pressures and high strain rates," $J$. Mater. Eng.Perform., pp. 1-21, 2014.

[44] B. P. Panda, S. Mohanty, and S. K. Nayak, "Polyolefin nanocomposites with enhanced photostability weathering effect on morphology and mechanical properties," J. Mater. Eng. Perform., vol. 23, pp. 3229-3244, 2014.

[45] R. Andrews, E. Grulke, and G. Kimber, "Mechanical properties of carbon fiber composites for environmental applications," Preprints of Papers, American Chemical Society, Division of Fuel Chemistry, vol. 41, 1996.

[46] M. Asghar, N. Iqbal, S.S. Iqbal, M. Farooq, and T. Jamil, "Ablation and thermo-mechanical tailoring of EPDM rubber using carbon fibers," J. Polym. Eng.

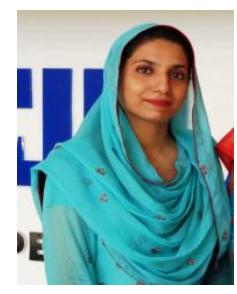

Sadia Sagar Iqbal is working as Assistant Professor in the Department of Polymer Engineering \& Technology, CEET, University of the Punjab, Lahore, Pakistan. She earned HEC indigenous fellowship for $\mathrm{PhD}$ and joined School of Chemical and Materials Engineering, National University of Sciences and Technology, Islamabad, Pakistan for MS and PhD studies in the discipline of Materials and Surface Engineering. She has a book from her 
MS research work on High Strength Composite Materials entitled "High Strength Composites: Synthesis and Mechanical Testing of Particle and Fiber Reinforced High Strength Composite Materials" that was published in 2010 by Verlag Dr. Muller (VDM), Germany. She presented her research work in eight international conferences and earned five best presentation awards. In her PhD research work, She builts a Thermal Insulation Testing Experimental Set Up to analyze the thermal conductivity/impedance at low/high temperatures. She reported the data from this home built setup in seven international journals. She has worked with Longman Mills Lahore, Pakistan as senior researcher. After that She had a chance to worked with many other industries like ATS coating industries, Escorts Internationals, Anwar Khawaja industries for synthetic fiber reinforced rubber composites for automotive industries, fire retardant nanocomposites for electric cables insulation, metal/Neoprene composites for shock absorber in bridge construction, NBR composites for bullet proof jackets, Development of polymer nanocomposites used to fabricate field hockey sticks, and development F-MWCNTs impregnated PDMS nanocomposite coatings on Kevlar fabric for safety apparels. Presently, she is working on "Synthesis/functionalization of nanofillers and their impact on polymeric materials regarding electrical, thermal and mechanical characteristics". She has very strong hand to work with SEM/EDS, FTIR, XRD, UTM, LCR meter, TG/DTA, DSC, Rheometer, and AFM. Twenty ISI index Impact factor research articles is on her credit. Total citation of 45 and h-index is 04 . She have strong prospective that are significant in the field of advanced research and teaching. 